\title{
A MYASTHENIC SYNDROME ASSOCIATED WITH BRONCHIAL CARCINOMA
}

\author{
R. P. WISE AND VIOLET MACDERMOT ${ }^{1}$ \\ From the Department of Anaesthetics and Neurology, St. Thomas's Hospital, London
}

It is now well recognized that certain patients with carcinoma of the bronchus show clinical features resembling, in some respects, those found in myasthenia gravis (Henson, 1953; Henson, Russell, and Wilkinson, 1954; Heathfield and Williams, 1954; MacKenzie and Hall, 1954; Shafar, 1954; Borrelli and Keen, 1954). It has also been found that some patients with bronchial carcinoma have abnormal responses to muscle relaxant drugs (Gray and Halton, 1948; Anderson, ChurchillDavidson, and Richardson, 1953; Croft, 1958). The term 'myasthenic syndrome' was introduced by Eaton and Lambert (1957) and Rooke, Lambert, and Eaton (1960) in order to distinguish this group of patients with carcinoma of the bronchus from those with classical myasthenia gravis.

The clinical features of the myasthenic syndrome, as described by Eaton and Lambert, consisted of weakness and fatiguability of muscles, sometimes limited to those of the pelvic girdle, depression of tendon reflexes, poor response to neostigmine, and marked sensitivity to tubocurarine. Electromyography showed a pattern of low-voltage, shortduration potentials, such as is found in myopathy, with no evidence of denervation. There was reduction in the initial amplitude of the muscle action potentials in response to nerve stimulation at slow rates and marked facilitation of the response at fast rates of stimulation, as shown by a progressive increase in the heights of the action potentials. The type of carcinoma, in those cases where histology was available, was in the majority of cases 'oat-cell' or anaplastic carcinoma of the bronchus.

The myasthenic syndrome is one of a number of neuromuscular syndromes which have been described as occurring in association with carcinoma of the bronchus. Cases of peripheral neuropathy-of sensory, motor, or mixed types-and of myopathy have been reported by a number of authors and the subject has been reviewed by Denny-Brown (1948), Lennox and Prichard (1950), Henson et al. (1954), and Heathfield and Williams (1954). The association of polymyositis and dermatomyositis with carcinoma, including bronchial carcinoma, has

${ }^{1}$ Leverhulme research scholar. similarly been described and reviewed by Domzalski and Morgan (1955) and by Walton and Adams (1958).

Three patients with a myasthenic syndrome similar to that described by Eaton and Lambert (1957) are presented in this paper. A detailed study was made in two cases using electromyographic and histological techniques. The findings confirm those of the above authors and provide additional evidence that this myasthenic syndrome is a condition distinct from myasthenia gravis.

The electromyographic technique used was that described by Churchill-Davidson and Richardson (1953). The ulnar nerve was stimulated supramaximally at the elbow and action potentials were recorded from the hypothenar muscles using surface electrodes. Recordings were made at both twitch (2.5/second) and tetanic (50/second) rates of stimulation. A control series was obtained and a comparison made with the electromyographic pattern obtained after the production of a partial neuromuscular block by injecting muscle relaxant drugs. Finally, an attempt was made to reverse the neuromuscular block by injecting anticholinesterase drugs (neostigmine or Tensilon), the electromyographic response again being recorded. The injections were all intravenous.

Neuromuscular blocking agents act in two main ways (see Table I). Depolarizing agents such as decamethonium and succinylcholine mimic the action of acetylcholine by producing an initial depolarization at the end-plate region. The neuromuscular block which develops is thought to be due either to a local area of inexcitability of the adjacent muscle membrane (Paton, 1956) or to a reduction in the sensitivity of the end-plate to the transmitter substance (Thesleff, 1956). Such a block is potentiated by anticholinesterase drugs.

Tubocurarine and similar drugs produce a nondepolarizing type of neuromuscular block by preventing the acetylcholine molecules from coming into contact with the receptor sites of the motor end-plates. The excitation threshold of the muscle fibre is raised but the liberation of acetylcholine is unaffected (McIntyre, 1947). Anticholinesterase 
drugs, by increasing the concentration of acetylcholine at the end-plate region, reverse this type of block (see Table I). The criteria used for distinguishing a depolarizing from a non-depolarizing neuromuscular block adopted in this paper are those laid down by Churchill-Davidson and Richardson (1953) and by Churchill-Davidson and Christie (1959). The effects of these drugs on the neuromuscular junction are sufficiently predictable for their use to form a valuable diagnostic procedure.

\section{CASE HISTORIES}

CASE 1 (NO. P 9976) A man, aged 51, was admitted to Westminster Hospital in December 1952 complaining of aching pains and progressive fatiguability and weakness in his legs for four months and in his arms for six weeks. The only abnormalities found in the central nervous system were right-sided deafness and slight weakness of the upper arms, the hip flexors, and the trunk flexors. The tendon reflexes were normal and the plantar responses were flexor. Sensation was normal, as were all other systems on clinical examination. Trial injections of neostigmine with control injections of saline were carried out. Neostigmine, $1.5 \mathrm{mg}$., produced some improvement, although it seemed to diminish his fatiguability rather than improve his muscular power and it was considered that clinically his condition resembled myasthenia gravis. He improved symptomatically on oral neostigmine, $15 \mathrm{mg}$. t.d.s., and was discharged home. Ten days later he was readmitted following an episode of sudden chest pain with cough and haemoptysis. The neostigmine tests were repeated and the previous results confirmed. The following procedures were carried out:

Results of laboratory investigations Haemoglobin $78 \%$, E.S.R. $26 \mathrm{~mm}$./one hour (Wintrobe), cerebrospinal fluid normal.

Bronchoscopy and bronchial biopsy (Sir Clement Price Thomas). This was performed under a local anaesthetic and showed stenosis of the apical branch of the left lower lobe bronchus. Microscopy (Dr. A. D. Morgan) showed an anaplastic carcinoma of the bronchus.

Thoracotomy (Mr. C. E. Drew) A hard mass was found occupying the left hilum and pneumonectomy was carried out.

After premedication with papaveretum $20 \mathrm{mg}$. and hyoscine $0.43 \mathrm{mg}$., anaesthesia was induced with thiopentone $400 \mathrm{mg}$. and tubocurarine $5 \mathrm{mg}$. and was con- tinued with nitrous oxide and oxygen using controlled respiration (Dr. A. W. Edridge). No additional doses of tubocurarine were required throughout the operation, which lasted about two hours.

Respiratory movements were barely perceptible and only slight improvement followed the intravenous injection of atropine $0.6 \mathrm{mg}$. and neostigmine $2.5 \mathrm{mg}$. Increments of neostigmine to a total of $10 \mathrm{mg}$. were given, producing an intractable flow of viscid saliva. After half an hour respiratory excursions appeared adequate. An hour later the patient collapsed, becoming pulseless, cyanosed, and apnoeic. Respiration and pulse returned after intubation and artificial ventilation with oxygen. His collapse was ascribed to respiratory failure due to a persistent neuromuscular block. After the first 24 hours he made a satisfactory rezovery but for some days complained of dysphagia, which improved after neostigmine.

On discharge home his limbs were subjectively stronger and he remained well for three months but then weakness became progressively worse. He died at home seven months after pneumonectomy. There was no necropsy.

CASE 2 (NO. 308314) A man, aged 55, was admitted to St. Thomas's Hospital in May 1960 complaining of aching and weakness of his arms and legs dating from an attack of bronchitis and haemoptysis three months before admission. Clinical examination on admission showed a fairly active man with early finger clubbing and moderate hypertension (blood pressure $210 / 130 \mathrm{~mm}$. $\mathrm{Hg}$ ). He was partially deaf and had moderate proximal weakness of the upper limbs, and generalized weakness of the lower limbs. The tendon reflexes were reduced but equal and plantar responses were flexor. Sensation was normal. No muscle tenderness and no skin lesions were demonstrated.

Results of laboratory investigations Plasma electrolytes, serum proteins, serum creatinine, and serum bilirubin were normal. Plasma pseudocholinesterase was normal. Serum creatine was increased to $1.9 \mathrm{mg} . / 100 \mathrm{ml}$.

Bronchoscopy and bronchial biopsy These had been performed without incident at the South Western Hospital in April 1960 under a combined local and general anaesthetic technique using $4 \%$ lignocaine and $150 \mathrm{mg}$. thiopentone. Microscopy (Dr. L. Hewlett) showed the presence of an anaplastic carcinoma of the bronchus.

Thoracotomy At thoracotomy (Mr. G. Kent Harrison) an inoperable growth was found invading the root of the right main bronchus and both pulmonary veins.

After premedication with papaveretum $10 \mathrm{mg}$. and 
hyoscine $0.43 \mathrm{mg}$., induction with thiopentone $300 \mathrm{mg}$. and suxamethonium chloride $100 \mathrm{mg}$. was followed by moderate muscular fibrillation. Endotracheal intubation was performed but spontaneous respiratory movements returned only after 10 to 15 minutes, after which $20 \mathrm{mg}$. tubocurarine was injected intravenously to establish controlled respiration. Anaesthesia was continued using a circle absorber (oxygen 1 litre/minute: nitrous oxide 3 litres/minute).

The operation was completed 50 minutes after beginning anaesthesia, and as there was no sign of spontaneous respiration, controlled respiration was continued. One hundred minutes later weak facial movements and feeble respiratory excursions were noted. Intravenous atropine $1 \mathrm{mg}$. followed by neostigmine $2.5 \mathrm{mg}$. were given in divided doses over three minutes, with slight improvement in respiratory excursion. Stimulation of the ulnar nerve at the wrist suggested the presence of a non-depolarizing (curare) type of neuromuscular block (Churchill-Davidson and Wise, 1960) (see Table I). Spontaneous respiration was established every half hour to assess its depth, but improvement was slow until 330 minutes after the operation. At this stage injection of atropine $1 \mathrm{mg}$. and neostigmine $2.5 \mathrm{mg}$. produced a marked increase in ventilation and at 370 minutes the endotracheal tube was re noved, although a slight tracheal tug and signs of a curare-type block were still present. Both during the operation and the postoperative period the blood pressure remained satisfactory. Adequate ventilation was maintained and periods of hyperventilation were carried out to exclude hypercarbia as a factor in the patient's apnoea.

Muscle biopsy A biopsy of the left biceps muscle was performed using the intravital methylene blue staining technique for intramuscular nerve fibres and motor endplates (Coërs, 1952). Microscopic examination of the routinely stained sections showed little obvious abnormality of the muscle fibres. Methylene-blue-stained sections showed irregularity of calibre and abnormal swellings of the axons of the intramuscular nerve fibres and the presence of a number of fine beaded fibres. The distal nerve fibres showed increased preterminal branching. Motor end-plates varied in size, but were mainly abnormally large and complex and often degenerate in appearance. The picture was not that hitherto seen in cases of myasthenia gravis (Coërs and Woolf, 1955; 1959; MacDermot, 1960) but would be consistent with a mild peripheral neuropathy (Figs. 1a, b, and c).

A course of oral neostigmine $15 \mathrm{mg}$. t.d.s. was given without clinical improvement in muscle power.

Electromyography The results in this patient and in myasthenia gravis are set out in Table IIa.

A needle-electrode recording (Dr. P. Bauwens) in the right deltoid and biceps showed no evidence of denerva-

\section{TABLE IIa}

ELECTROMYOGRAPHIC DIFFERENCES (USING SUPRAMAXIMAL STIMULI)

Normal Subject

(1) Controls

Initial height of potentials

Stimulation at twitch rates

Stimulation at tetanic rates

Post-tetanic facilitation

(2) Effect of small doses of given intermittently over 6 to 12 $\min$.

Character of neuromuscular block

Neostigmine or Tensilon (after decamethonium)

(3) Effect of small doses of tubocurarine $(5 \mathrm{mg}$.) Character of neuromuscular block

None control further reduced Table I)
Normal (approx. 6 to $12 \mathrm{mv}$ )

No change in height of potentials

No change in height of potentials

Myasthenia Gravis

Myasthenic Syndrome

Normal (low only if muscles Low clinically weak)

No change in height of potentials 'Fade' or 'fade'

No change in height of potentials or 'fade'

Often present

Sensitive, height of potentials falls Resistant, height of potentials from $100 \%$ to less than $20 \%$ of

Resistant, height of potentials
maintained near control level in most cases

(In severe generalized myasthenic weakness height of potentials may fall)

Range of height of potentials $100 \%$ to $30 \%$ of control

Depolarizing block (see Table I)

If height of potentials falls, a non-depolarizing type of block develops (see Table I)

Block may be potentiated, height of potentials unaltered or

Minimal signs of paralysis

Non-depolarizing block (see potentials Present (apnoea ensues)

(apno

(a) generalized weakness decamethonium (2.0 to $3.0 \mathrm{mg}$.)
Block reversed, height of poten tials increased

Increased sensitivity-clinically weak muscles most affected Non-depolarizing block, rapid fall in amplitude of potentials 'Fade' and post-tetanic facilitation present
Progressive increase in height of

Very sensitive, height of potentials falls to less than $20 \%$ of control

Before potentials are abolished they still progressively increase in height during tetanus: posttetanic facilitation present

Block reversed, height of potentials increased

Marked sensitivity producing

Very rapid fall in amplitude of potentials; before potentials are abolished they still progressively increase in height during tetanus; post-tetanic facilitation present

Effect of neostigmine or Tensilon (after tubocurarine)
Block reversed, increase in height of potentials
Block reversed, increase in height Block reversed, increase in height of potentials 

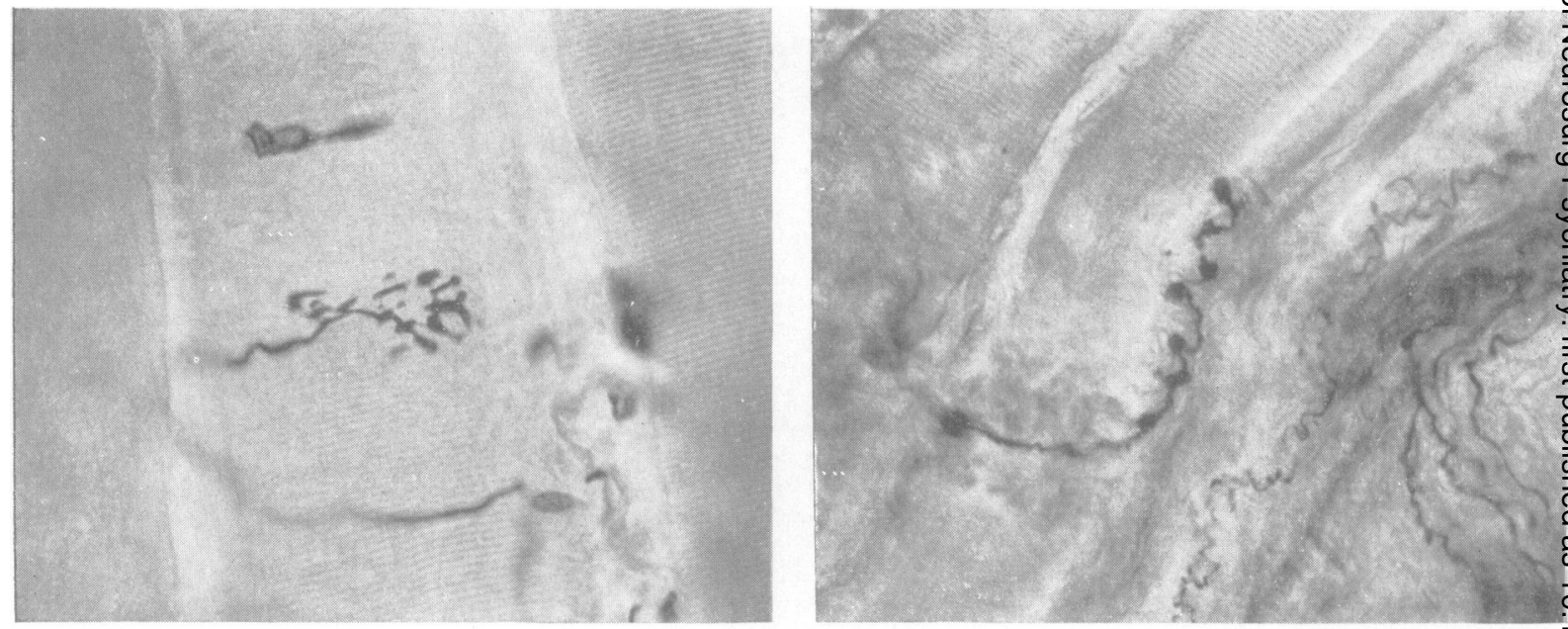

FIG. 1(a)

FIG. 1(b)

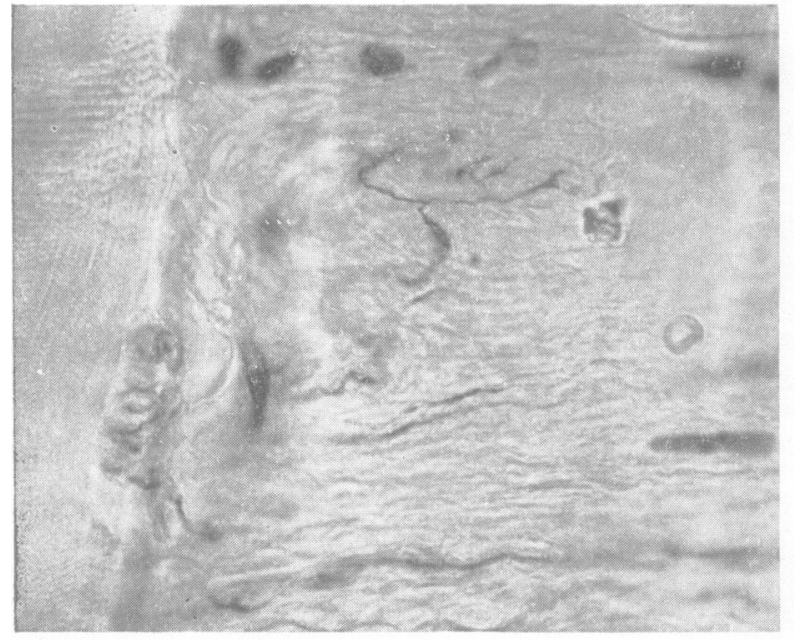

FIG. 1(c)

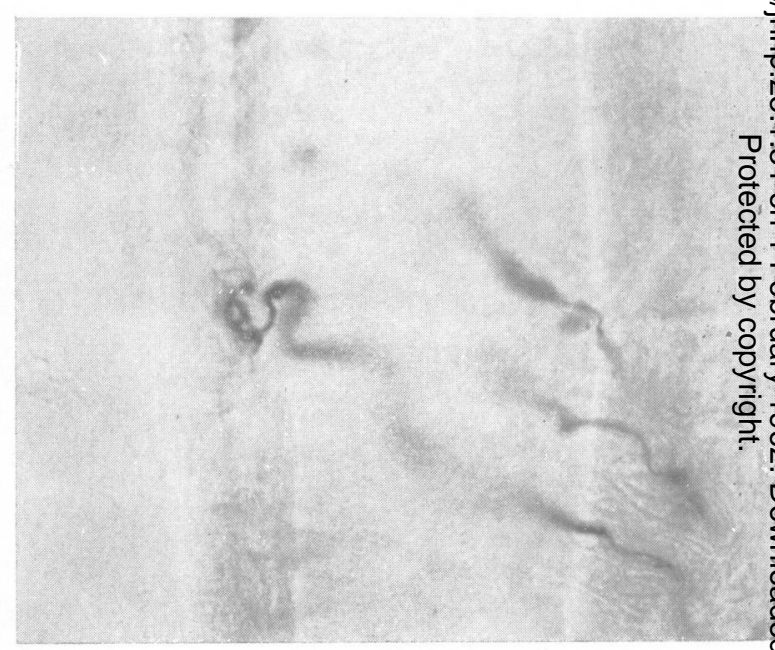

FIG. 1(d)

FIG. 1. Methylene blue stained sections $(\times 500)$.

(a) A normal motor end-plate, (b) an end-plate in a case of myasthenia gravis, (c) an end-plate in Case 2, and (d) an endplate in Case 3.

tion or of spontaneous activity in these muscles. On volition a complete pattern of short-duration potentials was obtained. High-frequency stimulation of the brachial plexus with recording of the action potentials in the biceps and deltoid showed an initial decrease in amplitude followed by a progressive increase during the period of stimulation.

The decamethonium test was performed under general anaesthesia (thiopentone $400 \mathrm{mg}$., pethidine $30 \mathrm{mg}$., and nitrous oxide and oxygen) using supramaximal stimulation.

(1) The control electromyogram before decamethonium was given showed the following features:-At twitch rates of stimulation $(2 \cdot 5 /$ second) successive potentials showed a progressive diminution in size (Fig. 2a) and were smaller than would be expected in relation to the muscular power. At tetanic rates of stimulation (50/ second) the potentials showed a brief initial 'fade' followed by a striking and progressive 'growth' of successive potentials until they attained a height of almost $300 \%$ compared with the original size (Figs. $2 b$ and c). Stimulation at twitch rates $(2.5 /$ second) immediately after a burst of tetanus showed the presence of posttetanic facilitation with only slight 'fade' (Fig. 2d).

(2) After $2.0 \mathrm{mg}$. decamethonium the patient became apnoeic and the action potentials almost disappeared at 


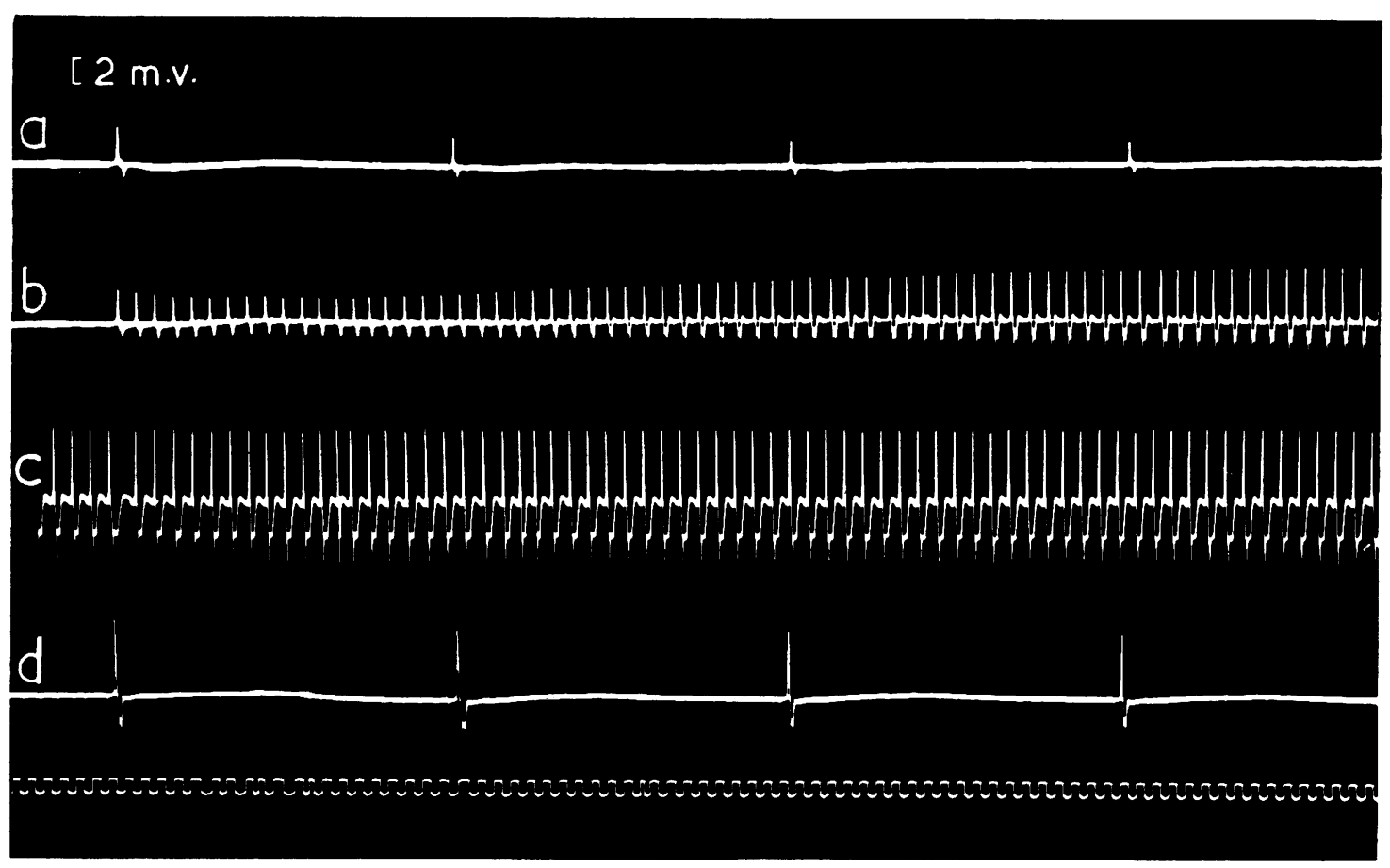

FIG. 2. Electromyographic recordings in Case 2 at twitch and tetanic rates of stimulation. (Time base $0.01 /$ sec.)

(a) 2.5/second (twitch) showing low voltage potentials and 'fade'.

(b) 50/second (tetanus) showing small initial 'fade' followed by progressive 'growth' of successive potentials.

(c) 50/second (tetanus) continuation of recording (b) after five seconds, showing 'growth' of potentials to almost $300 \%$ of the initial height.

(d) 2.5/second (twitch) showing post-tetanic facilitation.

both twitch and tetanic rates of stimulation. Twenty-two minutes after the decamethonium the potentials at twitch rates had returned to $65 \%$ of their original height, although the response to tetanus was still only $14 \%$ and failed to show the degree of growth observed in the control series (Fig. 4c). At this time spontaneous respiration had restarted but was inadequate and required assistance.

(3) The residual neuromuscular block was improved initially with Tensilon $10 \mathrm{mg}$. intravenously and then with neostigmine $2.5 \mathrm{mg}$. and atropine $1 \mathrm{mg}$. given in divided doses. Twelve minutes after these injections the response to twitch rates of stimulation had improved, even beyond the height of the control series, to $121 \%$.

Subsequent course The patient was discharged home for four weeks, and on readmission neuromuscular transmission was further investigated. On this occasion $10 \mathrm{mg}$. Tensilon was given intravenously, which produced transient improvement in the height of the action potentials at twitch and at tetanic rates of stimulation while the growth on tetanus was unchanged. The patient died at home about six months from the onset of his symptoms. There was no necropsy.

CASE 3 (No. 320474) A man, aged 57, was admitted to St. Thomas's Hospital in December 1960 with a five months' history of fatigue on exertion and progressively increasing weakness of the arms and legs. In addition he noticed intermittent double vision and drooping of the left eyelid, hoarseness, aching of the limbs on exertion, and pain in the lower back and abdomen. On admission he was able to walk about 50 yards. Examination of the central nervous system showed slight left ptosis and bilateral facial weakness, weakness of the limb girdles and trunk, and absent tendon reflexes apart from the supinator jerks. General examination showed abdominal distension, the liver edge being tender and palpable 1 in. below the costal margin. No skin lesions or muscle tenderness were noted.

Results of laboratory investigations Serum electrolytes and blood urea were normal. Serum creatinine 1.18 mg. $\%$. Serum creatine $0.52 \mathrm{mg}$. $\%$. Serum electrophoresis showed increased $\gamma$ globulin. Serum bilirubin $2.3 \mathrm{mg}$. \%. E.S.R. $30 \mathrm{~mm}$. in one hour (Westergren). Serum pseudocholinesterase normal. Cerebrospinal fluid was normal.

Bronchoscopy and bronchial biopsy (Mr. G. Kent Harrison) This was performed under a combined local and general anaesthetic using thiopentone and $4 \%$ lignocaine. A mass of carcinoma was found replacing the orifice of the apical branch of the right lower lobe bronchus. 
Microscopy (Dr. J. L. Pinniger) showed a poorly differentiated ('oat-cell') carcinoma of the bronchus.

Muscle biopsy Biopsy of the left deltoid showed little abnormality of the muscle fibres on routine staining. Methylene-blue-stained sections showed increased preterminal branching of the nerve fibres with swellings and irregularities along the axons. The motor end-plates showed degenerative changes. The appearances were those of a distal neuropathy (Fig. 1d).

Neostigmine therapy The response to oral neostigmine $15 \mathrm{mg}$. t.d.s. was doubtful but there appeared to be slight improvement in hand grip. The intramuscular injection of $1.5 \mathrm{mg}$. neostigmine produced a definite improvement. The patient tired less readily and he was able to walk five times the original distance.

Electromvography The decamethonium test was performed under general anaesthesia (thiopentone $400 \mathrm{mg}$., pethidine $30 \mathrm{mg}$., and nitrous oxide and oxygen) as in Case 2 (Table IIa).

(1) The control electromyogram showed the characteristic low-voltage potentials on supramaximal stimulation with 'fade' at twitch rates (Fig. 3a), 'growth' with tetanus to more than $500 \%$ compared with the initial potential (Figs. 3b and c) and post-tetanic facilitation (Fig. 3d).

(2) To test the effect of decamethonium, $2 \cdot 5 \mathrm{mg}$. was given over a period of six minutes. Three minutes after the initial dose of $1.5 \mathrm{mg}$. the height of the potentials at twitch rates had increased to $260 \%$ compared with the control. This initial improvement was followed by a rapid fall in the height of the potentials and after 13 minutes the height of the action potentials during tetanus had fallen to $17 \%$ compared with the control series and respiratory activity had almost entirely ceased.

(3) The effect of neostigmine was tested by giving $2.5 \mathrm{mg}$. neostigmine and $1.0 \mathrm{mg}$. atropine and at this stage improved respiration in three minutes, and after six minutes the potentials at twitch rates had returned to their original level but the tetanic and post-tetanic responses were still only $67 \%$ of the control level (Fig. $4 d)$.

On another occasion small doses of tubocurarine were injected while the patient was conscious and the electromyographic recordings were made from the hypothenar muscles during supramaximal stimulation of the ulnar nerve. After $1.0 \mathrm{mg}$. tubocurarine the height of the action potentials at twitch rates fell to $76 \%$ and the post-tetanic response to $28 \%$ compared with the control (pre-injection) series. The height to which the potentials grew during tetanus was unaltered but the growth was more rapid and the maximum height was attained after 2.5 seconds compared with six seconds in the control series. After $4 \mathrm{mg}$. tubocurarine given over a period of 10 minutes, the height
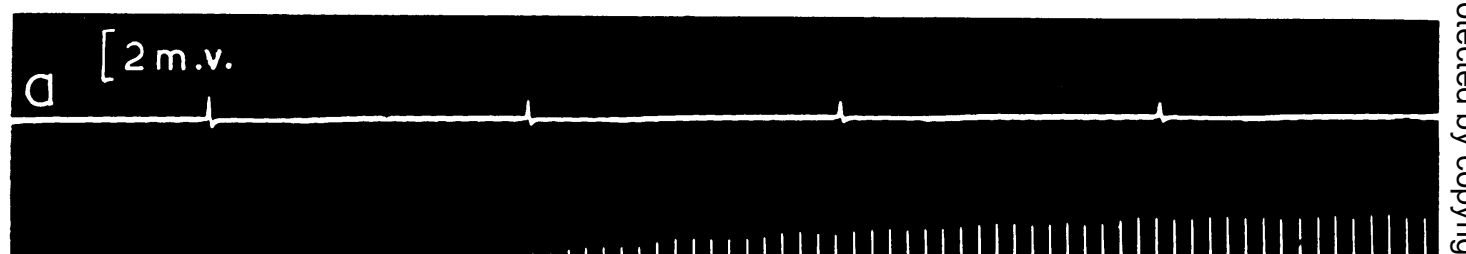

FIG. 3. Electromyographic recordings in Case 3 at twitch and tetanic rates of stimulation. (Time base $0.01 / \mathrm{sec}$.)

(a) 2.5/second (twitch) showing low voltage potentials and 'fade'.

(b) 50/second (tetanus) showing small initial 'fade' followed by progressive 'growth' of successive potentials.

(c) $50 /$ second (tetanus) continuation of recording (b) after five seconds, showing 'growth' of potentials to more than $500^{\circ}$ 。 of the initial height.

(d) $2 \cdot 5 /$ second (twitch) showing post-tetanic facilitation. 


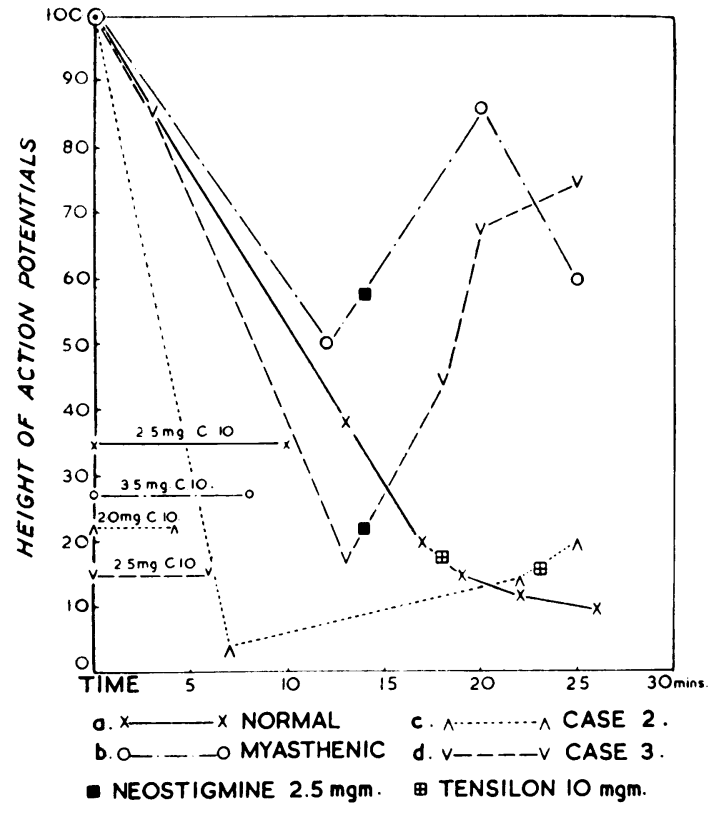

FIG. 4. Graph showing effect of decamethonium (C.10) on the maximum height of the action potentials recorded during tetanus (control potential before C.10 = 100) and the subsequent response to Tensilon or neostigmine.

(a) Normal person: $2.5 \mathrm{mg}$. of C.10, neuromuscular transmission decreased by Tensilon $10 \mathrm{mg}$.

(b) Myasthenia gravis: $3.5 \mathrm{mg}$. of C.10, neuromuscular transmission improved by neostigmine $2.5 \mathrm{mg}$.

(c) Case 2: $2.0 \mathrm{mg}$. of C.10, neuromuscular transmission improved by Tensilon $10 \mathrm{mg}$.

(d) Case 3: $2.5 \mathrm{mg}$. of C.10, neuromuscular transmission improved by neostigmine $2.5 \mathrm{mg}$.

of the action potentials were reduced to $8 \%$ at twitch rates, to $23 \%$ during tetanus, and to $23 \%$ after tetanus. At this stage the patient felt very weak and was dysarthric. He had marked ptosis, was unable to protrude his tongue, and could only just raise his heel from the bed. These signs disappeared following the injection of $2.5 \mathrm{mg}$. neostigmine and after six minutes the height of the action potentials had returned almost to their original level. For the following 24 hours the patient complained of increased weakness and he was unable to walk.

The effect of neostigmine upon neuromuscular fatigue was investigated. An injection of $2.5 \mathrm{mg}$. of the drug intravenously during fatigue induced by nerve stimulation increased the height of the action potentials from $84 \%$ to $110 \%$ at twitch rates and from $92 \%$ to $115 \%$ at tetanic rates of stimulation after a period of 12 minutes.

Subsequent course The patient was discharged and died at home three months later. No necropsy was performed.

\section{DISCUSSION}

The history of progressive fatiguability and weakness of the proximal limb muscles, the finding of improvement with neostigmine in Cases 1 and 3, and the abnormal sensitivity to tubocurarine in all cases suggested a diagnosis of myasthenia gravis. Clinically, however, the presence of aching pains in the limbs, together with the lack of involvement in two cases of external ocular, facial, and bulbar muscles, differentiate this syndrome from typical myasthenia gravis (see Table IIb). The presence of anaplastic carcinomata of the bronchus served to relate the present cases to those reported by Rooke et al. (1960). The lack of response to oral neostigmine in Cases 2 and 3 was not typical of myasthenia gravis and in similar cases other investigators have usually found little response to oral neostigmine whereas injection of the drug was often followed by more obvious improvement.

Electromyographic findings in Cases 2 and 3 were not those characteristic of myasthenia gravis (see Table IIa). The muscle action potentials produced by supramaximal stimulation were initially abnormally small but after an initial decrease in size the heights of the potentials gradually increased to 300 and $500 \%$ of the original heights on fast repetitive nerve stimulation (see Fig. $2 b$ and c and Fig. $3 b$ and c). These features were described in such cases by Eaton and Lambert (1957). In our experience no comparable increase in height of potentials during the course of tetanic stimulation has been found in myasthenia gravis. On the contrary, in cases of mysasthenia gravis with muscular fatiguability or weakness, tetanic stimulation produces a rapid decrease in the height of the muscle action potentials followed by a period during which post-tetanic facilitation can be demonstrated (Johns, Grob, and Harvey, 1956). Responses similar to those obtained in myasthenia gravis are seen in normal subjects after the administration of tubocurarine (ChurchillDavidson and Christie, 1959).

A further distinguishing feature was the response to decamethonium and tubocurarine. Patients with myasthenia gravis, with muscular power comparable to that of the present cases, show characteristic resistance to the depolarizing action of decamethonium and reversal of the eventual block by neostigmine or Tensilon (Churchill-Davidson and Richardson, 1953) (see Fig. 4b). In Cases 2 and 3 the marked fall of the action potentials after $2 \mathrm{mg}$. and $2.5 \mathrm{mg}$. decamethonium respectively indicated sensitivity to this drug, and the neuromuscular block so produced was partially reversed by neostigmine. In a normal person after $2.5 \mathrm{mg}$. decamethonium the height of the action potentials falls to about $20 \%$ and the neuromuscular block is increased by neostigmine or Tensilon (see Fig. 4a). Tubocurarine in a dose of $20 \mathrm{mg}$. produced paralysis for six hours in Case 2; $5 \mathrm{mg}$. had a similar but some- 
TABLE IIb

DIFFERENCES BETWEEN MYASTHENIA GRAVIS AND MYASTHENIC SYNDROME

\begin{tabular}{|c|c|c|}
\hline & Myasthenia Gravis & Myasthenic Syndrome \\
\hline $\begin{array}{l}\text { Age of onset } \\
\text { Association with malignant disease }\end{array}$ & $\begin{array}{l}\text { Any age } \\
\text { Thymoma (approximately } 10 \% \text { of cases) }\end{array}$ & $\begin{array}{l}\text { Middle life } \\
\text { Carcinoma of bronchus (anaplastic or 'oat } \\
\text { cell') }\end{array}$ \\
\hline $\begin{array}{l}\text { Weakness of external ocular, bulbar, and } \\
\text { facial muscles }\end{array}$ & Frequent (often the presenting sign) & Unusual \\
\hline Weakness of limbs & Usually proximal, arms $>$ legs & $\begin{array}{l}\text { Proximal, legs }>\text { arms (usually the presenting } \\
\text { sign) }\end{array}$ \\
\hline $\begin{array}{l}\text { Muscular pain and tenderness } \\
\text { Tendon reflexes } \\
\text { Response to intravenous neostigmine } \\
\text { Prognosis }\end{array}$ & $\begin{array}{l}\text { Absent } \\
\text { Usually present } \\
\text { Usually good } \\
\text { Often good, except when thymoma } \\
\text { present }\end{array}$ & $\begin{array}{l}\text { Frequently present } \\
\text { Usually depressed } \\
\text { Usually slight or moderate } \\
\text { Rapid deterioration and death }\end{array}$ \\
\hline
\end{tabular}

what shorter effect in Case 1 but in Case 3, $4 \mathrm{mg}$. almost completely abolished neuromuscular transmission and the electromyographic recordings were not typical of a non-depolarizing block (see Table I). Thus there appeared to be an abnormal response both to depolarizing and to non-depolarizing types of muscle relaxant drugs. Cases 2 and 3 showed some reduction in the height of the action potentials as electromyography proceeded, most marked after the initial stimulation. Spontaneous recovery was slow but restoration of the potentials to normal followed the injection of neostigmine. This response is in keeping with the clinical observation that in patients with myasthenia associated with carcinoma the injection of neostigmine reduces fatiguability rather than increases muscular power.

Histologically the appearances in Cases 2 and 3 were not those usually seen in myasthenia gravis (Coërs and Woolf, 1955, 1959; Bickerstaff and Woolf, 1960; MacDermot, 1960) and the pattern was of a non-specific degenerative process affecting the distal nerves and motor end-plates. In myasthenia gravis the end-plates have been found to present an abnormally elongated appearance even in the absence of abnormality of muscle fibres (see Figs. $1 b$, c, and d).

Masland and Gammon (1949) reported that the action potentials recorded from a muscle poisoned with botulinus toxin were smaller than normal and showed a progressive increase in size during tetanic stimulation of the nerve. Neostigmine failed to reverse the neuromuscular block. Since it has been shown by Guyton and MacDonald (1947) and by Burgen, Dickens, and Zatman (1949) that the output of acetylcholine on motor nerve stimulation in botulinus poisoning is greatly reduced, it is possible that in the myasthenic syndrome the output of acetylcholine at the neuromuscular junction is similarly reduced. Decamethonium stimulates by depolarizing the end-plate region before it paralyses. It was noteworthy, therefore, that in Case 3 following the first dose of decamethonium the height of the action potentials at twitch rates of stimulation increased to more than twice that present in the control. The enhanced effect upon supramaximal stimulation suggested that decamethonium was acting more effectively than the naturally released transmitter possibly because of deficient production of the latter. The suggestion that in myasthenia gravis there is, at the neuromuscular junction, a prejunctional deficiency of transmitter substance has been made by Desmedt (1957) and by Dahlbäck, Elmqvist, Johns, Radner, and Thesleff (1961), the latter workers using microelectrode techniques. Thus it is possible that in both the myasthenic syndrome and in true myasthenia gravis there is a defect in the output of transmitter substance. The physiological basis for the difference between the two conditions is not clear, and there is as yet no explanation for the prot gressive increase in amplitude of muscle action potentials on tetanic stimulation seen in the myas? thenic syndrome. The phenomenon of 'resistance' to decamethonium which occurs in myasthenia gravis is possibly due to an altered response by the motor end-plates (Churchill-Davidson and Richardson, 1953).

A clinical picture resembling myasthenia gravis has been reported in patients with thyroid disease (McEachern and Ross, 1942; Laurent, 1944; Sheldon and Walker, 1946; Millikan and Haines, 1953), with polymyositis (Reese and Harman, 1954; Bonduelle, Bouygues and Coulon, 1955), and with nutritional disorders (Denny-Brown. 1947). It is likely that it will be possible to differentiate the myasthenic syndrome which occurs in these conditions from myasthenia gravis by means of techniques similar to those used with the present cases.

If the myasthenic syndrome is present or suspected in patients with carcinoma of the bronchus, there is a potential risk in using both depolarizing and nondepolarizing types of muscle relaxant drugs during anaesthesia, especially the non-depolarizing agents. In such cases the non-depolarizing drugs are better avoided as even the usual test dose of tubocurarine 
(5 mg.) may be followed by a prolonged neuromuscular block.

\section{SUMMARY}

The literature relating to a 'myasthenic syndrome' associated with carcinoma of the bronchus is briefly reviewed.

Clinical descriptions are given of three cases, in two of which electromyographic and histological investigations were carried out.

The differences between the myasthenic syndrome and true myasthenia gravis are discussed and tabulated.

The possible risk attached to the use of muscle relaxant drugs in such cases is noted.

For permission to publish we should like to thank Mr. C. E. Drew, Dr. S. P. Meadows, and Sir Clement Price Thomas for Case 1, Mr. G. Kent Harrison, Dr. R. E. Kelly, and Dr. C. E. W. Wheaton for Case 2, and Dr. J. St. C. Elkington and Mr. G. Kent Harrison for Case 3. We are indebted to Dr. P. Bauwens, Dr. L. Hewlett, Dr. A. D. Morgan, and Dr. J. L. Pinniger for permission to publish their findings and to Professor R. C. Curran for facilities in the Department of Pathology. We are particularly grateful to Dr. H. C. Churchill-Davidson for helpful advice and criticism.

We should like to thank Mr. A. H. Spicer for the histological preparations, Mr. A. E. Clark for the photomicrographs, Mr. T. W. Brandon for the photographic film records, and Miss J. Davenport for secretarial help.

\section{REFERENCES}

Anderson, H. J., Churchill-Davidson, H. C., and Richardson, A. T. (1953). Lancet, 2, 1291.

Bickerstaff, E. R., and Woolf, A. L. (1960). Brain, 83, 10.

Borrelli, V. M., and Keen, H. (1954). Lancet, 1, 315.

Bonduelle, M., Bouygues, P., and Coulon, J. (1955). Rev. neurol., 92, 546.

Burgen, A. S. V., Dickens, F., and Zatman, L. J. (1949). J. Physiol. (Lond.), 109, 10.

Churchill-Davidson, H. C., and Christie, T. H. (1959). Brit. J. Anaesth, 31, 290.

—, and Richardson, A. T. (1953). J. Physiol. (Lond.), 122, 252.

_, and Wise, R. P. (1960). Brit. J. Anaesth., 32, 384.
Coërs, C. (1952). J. Neurol. Neurosurg. Psychiat., 15, 211.

—, and Woolf, A. L. (1955). C. R. Congr. Méd. Clin. Alien. Neurol., p. 137. Masson, Paris.

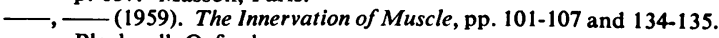
Blackwell, Oxford.

Croft, P. B. (1958). Brit. med. J., 1, 181.

Dahlbäck, O., Elmqvist, D., Johns, T. R., Radner, S., and Thesleff, S. (1961). J. Physiol. (Lond.), 155, 57P.

Denny-Brown, D. (1947). Medicine (Baltimore), 26, 41.

- (1948). J. Neurol. Neurosurg. Psychiat., 11, 73.

Desmedt, J. E. (1957). Nature (Lond.), 179, 156.

Domzalski, C. A., and Morgan, V. C. (1955). Amer. J. Med., 19, 370.

Eaton, L. M., and Lambert, E. H. (1957). J. Amer. med. Ass., 163, 1117.

Gray, T. C., and Halton, J. (1948). Brit. med. J., 1, 784.

Guyton, A. C., and MacDonald, M. A. (1947). Arch. Neurol. Psychiat. (Chicago), 57, 578

Heathfield, K. W. G., and Williams, J. R. B. (1954). Brain, 77, 122.

Henson, R. A. (1953). Proc. roy. Soc. Med., 46, 859.

—, Russell, D. S., and Wilkinson, M. (1954). Brain, 77, 82.

Johns, R. J., Grob, D., and Harvey, A. M. (1956). Bull. Johns Hopk. Hosp., 99, 125.

Laurent, L. P. E. (1944). Lancet, 1, 87.

Lennox, B., and Prichard, S. (1950). Quart. J. Med., 19, 97.

MacDermot, V. (1960). Brain, 83, 24.

McEachern, D., and Ross, W. D. (1942). Ibid, 65, 181.

McIntyre, A. R. (1947). Curare: Its History, Nature, and Clinical Use, p. 105. University of Chicago Press.

MacKenzie, I., and Hall, J. M. (1954). Lancet, 1, 108.

Masland, R. L., and Gammon, G. D. (1949). J. Pharmacol., 97, 499.

Millikan, C. H., and Haines, S. F. (1953). A.M.A. Arch. intern. Med., 92, 5.

Paton, W. D. M. (1956). Proceedings of the Conference on the Myoneural Junction, ed. E. M. Papper and E. J. de Beer, Columbia University and Burroughs, Wellcome \& Co., (U.S.A.) Inc., New York.

Reese, H. H., and Harman, J. W. (1954). Trans. Amer. neurol. Ass., 79, 82.

Rooke, E. D., Lambert, E. H., and Eaton, L. M. (1960). News Letter, Amer. Ass. Electromyog. and Electrodiag., 7, August, p. 11.

Shafar, J. (1954). Lancet, 1, 109.

Sheldon, J. H., and Walker, R. M. (1946). Ibid., 1, 342.

Thesleff, S. (1956). Acta physiol. scand., 37, 330.

Walton, J. N., and Adams, R. D. (1958). Polymyositis. Livingstone, Edinburgh and London.

\section{ADDENDUM}

Since this paper was prepared three further cases of this 'myasthenic syndrome' associated with bronchial carcinoma have been investigated and they all had the characteristic electromyographic and clinical features of the syndrome. 